\title{
A retrospective study of CT-guided percutaneous irreversible electroporation (IRE) ablation: clinical efficacy and safety
}

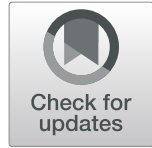

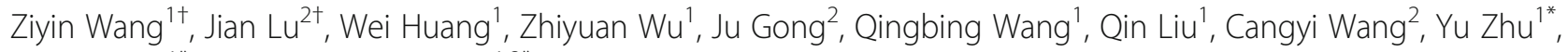
Xiaoyi Ding ${ }^{1 *}$ and Zhongmin Wang ${ }^{1,2^{*}}$ (i)

\begin{abstract}
Background: To evaluate the clinical efficacy and safety of ablating renal cell carcinoma (RCC) by irreversible electroporation (IRE).

Methods: Fifteen patients (19 lesions) with RCC who underwent IRE were retrospectively reviewed. Seven patients had solitary kidneys. Two lesions were located in the renal hilus. One patient had chronic renal insufficiency. Percutaneous biopsy for histopathology was performed. The best puncture path plan was evaluated before CTguided IRE. The estimated glomerular filtration rate (eGFR) was compared vs baseline at 1-2 months after the ablation. Contrast-enhanced computed tomography imaging changes were evaluated immediately after IRE. Contrast-enhanced computed tomography/magnetic resonance was performed 1 month, 3 months, 6 months, 12 months and every year thereafter. The complications after treatment were also reviewed.

Results: The success rate of the procedure was 100\%. The median tumor size was 2.4 (IQR 1.3-2.9) cm, with an median score of 6 (IQR 5.5-8) per R.E.N.A.L. criteria (radius, exophytic/endophytic, nearness to collecting system or sinus, anterior/posterior, and location relative to polar lines). Two cases (3 lesions) were punctured through the liver. In other cases, puncture was performed through the perirenal space. There were no severecomplications in interventional therapy. Transient gross hematuria occurred in 2 patients (centrally located). Self-limiting perinephric hematomas occurred in 1 patient. Needle puncture path metastasis was found in 1 patient 2.5 years after IRE. The subcutaneous metastasis was surgically removed, and there was no evidence of recurrence. There was no significant change in eGFR levels in terms of short- term clinical outcomes $(t=0.348, P=0.733)$. At 6 months, all 15 patients with imaging studies available had no evidence of recurrence. At 1 year, 1 patient (1 of 15) was noted to have experienced needle tract metastasis and accepted salvage radiofrequency ablation (RFA) therapy.
\end{abstract}

Conclusions: IRE appears to be a safe and effective treatment for RCC that may offer a tissue-sparing method and complete ablation as an alternative therapy for RCC.

Keywords: Carcinoma, Renal cell, Ablation techniques, Computed tomography

\footnotetext{
* Correspondence: zy10478@rjh.com.cn; dxy10456@rjh.com.cn;

wzm11896@rjh.com.cn

'Ziyin Wang and Jian Lu contributed equally to this work and shared the first authorship.

'Department of Radiology, Ruijin Hospital, School of Medicine, Shanghai Jiao

Tong University, 197\#, Rui Jin Er Road, Shanghai 200025, People's Republic of China

Full list of author information is available at the end of the article
}

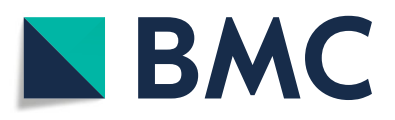

(- The Author(s). 2021 Open Access This article is licensed under a Creative Commons Attribution 4.0 International License, which permits use, sharing, adaptation, distribution and reproduction in any medium or format, as long as you give appropriate credit to the original author(s) and the source, provide a link to the Creative Commons licence, and indicate if changes were made. The images or other third party material in this article are included in the article's Creative Commons licence, unless indicated otherwise in a credit line to the material. If material is not included in the article's Creative Commons licence and your intended use is not permitted by statutory regulation or exceeds the permitted use, you will need to obtain permission directly from the copyright holder. To view a copy of this licence, visit http://creativecommons.org/licenses/by/4.0/. The Creative Commons Public Domain Dedication waiver (http://creativecommons.org/publicdomain/zero/1.0/) applies to the data made available in this article, unless otherwise stated in a credit line to the data. 


\section{Background}

Renal cell carcinoma (RCC) now has the second-highest incidence rate among all malignant tumors of the urinary system. With the evolution and popularity ofinterventional treatment technology, the European Association of Urology (EUA) has recommendedablative therapies for completely destroying tumor tissue and minimizing the injury of normal tissues in the guidelines for the treatment of RCC [1]. Traditional thermal ablation modalities such as radiofrequency ablation (RFA) and microwave ablation (MWA) use extreme temperatures to destroy target tissue. Therefore, thermal collateral damage to adjacent structures and heterogeneous ablation zones due to the heatsink effect are shortcomings. Irreversible electroporation (IRE) is a minimally invasive tumor ablative technique that has emerged in recent years. Although the precise mechanism by which IRE causes cell death remains to be elucidated, its theoretical advantage lies in its ability to induce apoptosis without thermal energy [2-5]. IRE is thought to spare surrounding structures such as blood vessels, connective tissue, and nerves [2]. Therefore, IRE represents an interesting option for the nephron-sparing treatment of renal tumors, even for those with an unfavorable anatomic location (e.g., centrally located and close to the renal pelvis and/or the large hilar vessels). The purpose of the present study was to evaluate the clinical efficacy and safety of RCC to provide a new treatment modality for renal cell carcinoma even in unfavorable anatomic locations and patients with renal insufficiency.

\section{Methods}

This retrospective study was approved by the institutional review board. There was no financial or industry support obtained.

\section{Patients}

From February 2017 to August 2019, 15 patients with 19 RCC lesions treated with IRE were included in the data analysis (Table 1 and Table 2).

Patients must meet the following conditions to participate in this research:

1. Complete medical record materials were available and the concomitant diseases were well controlled after treatment.

2. Routine blood count: leucocyte count $\geq 3 * 10^{9} / 1$, neutrophil count $\geq 2 * 10^{9} / 1$, hemoglobin $\geq 90 \mathrm{~g} / \mathrm{l}$, the platelet count $\geq 100 * 10^{9} / 1$.

3. 3.DIC: prothrombin time:(international normalized ratio, INR) $\geq 1.5$.

4. Liver and kidney functions: serum total bilirubin (TBIL) < 75umol /l, direct bilirubin (DBIL) < 39umol/l.
5. Patients who have not the surgical indication or nor willing to accept surgical treatment.

6. The expecting life span $\geq 6$ months.

\section{Exclusive criteria:}

1. Patients who have severe coronary artery disease,myelosuppression, acute or chronic infectious diseases, or cannot tolerate general anesthesia.

2. Patients who have coagulation disorders.

3. The preoperative imaging examinations confirmed no distant metastasis.

Eight of the patients were men, and 7 were women, with ages ranging from 51 to 84(median of 63 (IQR 54.5-68) years). Among them, 7 patients underwent nephrectomy for contralateral renal cancer. Four patients had two lesions in the ipsilateral kidney. One patient had nephrotic syndrome. The results of percutaneous biopsy for histopathology were renal clear cell carcinoma. Seventeen of the tumor locations were peripheral, and the other two were centrally located. The selection of the therapy modality was determined by the evaluation of the clinical multidisciplinary comprehensive treatment team. The patients' characteristics are listed in Table 1. Routine blood count,liverfunction and renal function (blood urea nitrogen, eGFR) were obtained within 3 days before IRE treatment.

\section{Preanesthetic preparation and anesthesia management} After a patient entered the operating room,venous access, noninvasive blood pressure, five-lead electrocardiogram and pulse oxygen saturation were established. General anesthesia was combined intravenous and inhalation anesthesia by tracheal intubation and venous access. Drugs for general anesthesia induction included fentanyl (2txg/ $\mathrm{kg}$ ),propofol $(2 \mathrm{mg} / \mathrm{kg})$, and rocuronium $(0.6 \mathrm{mg} / \mathrm{kg})$. Intravenous pumping of Diprivan (50-150 $\mathrm{mg} / \mathrm{h}$ ) and inhalation of sevoflurane were used for anesthesia maintenance. Then, enhanced CT scanning was performed to determine the exact size of the tumors,surrounding structures and best puncture path.

\section{Irreversible electroporation procedure}

The Nanoknife ${ }^{\circledR}$ System (AngioDynamics, Latham, New York) for IRE was used. The electrodes' effective exposure length was approximately $1-2 \mathrm{~cm}$. Three or four electrodeswere placed under CTguidance around the boundary of the renal tumors according to the size of the tumor. Partial zonal treatment was conducted with the tumor lesion between $2.5 \mathrm{~cm}$ and $4.5 \mathrm{~cm}$ to achieve adequate,overlapping therapeutic ablation coverage. The usual treatment region covered atumor-free margin of 5 


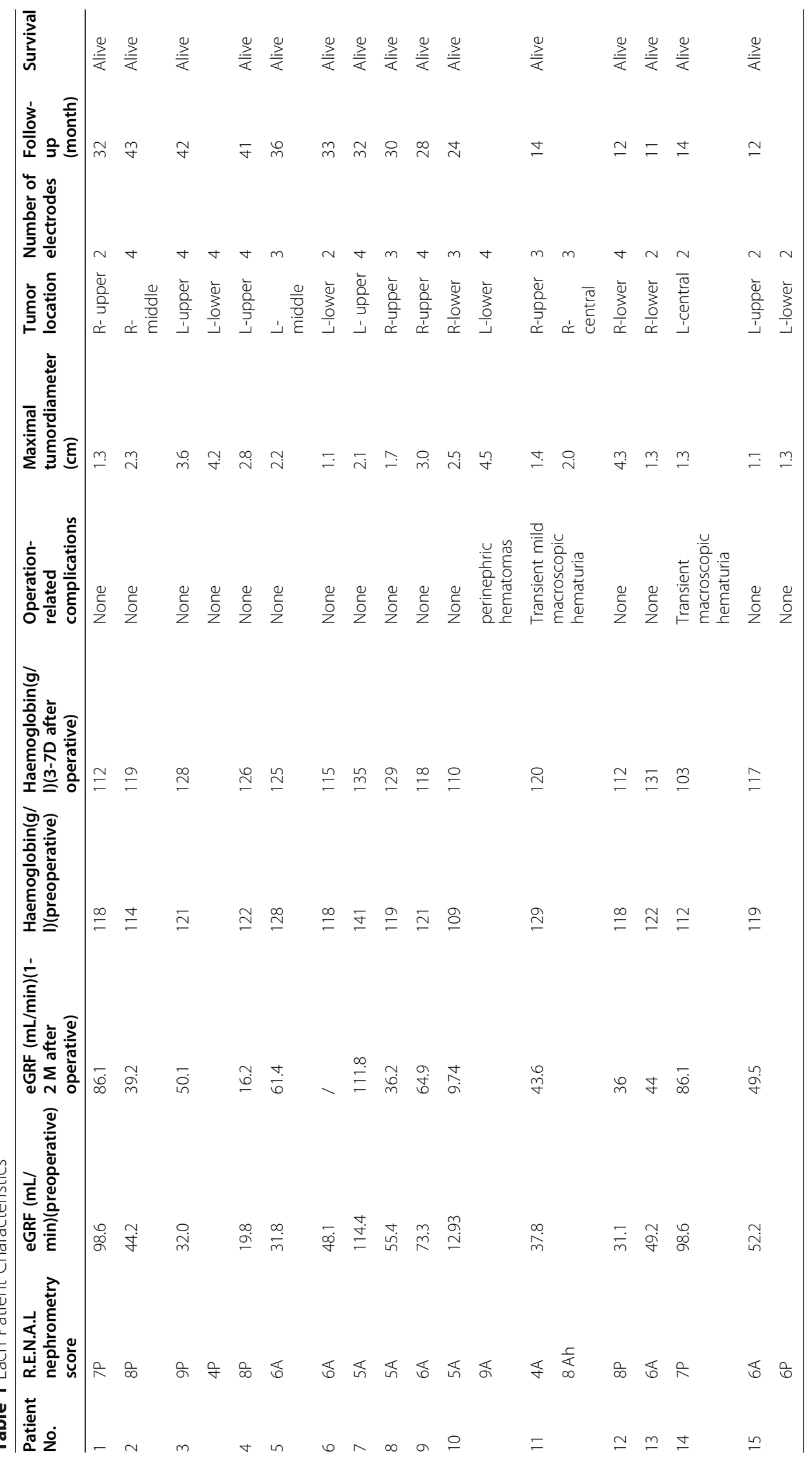


Table 2 Overall Patient Characteristics

\begin{tabular}{|c|c|}
\hline Patient and tumor characteristics & $\begin{array}{l}n=15 \text { patients } \\
(n=19 \text { tumors })\end{array}$ \\
\hline Tumor size $(\mathrm{cm})$, median (IQR) & $2.4(1.3-2.9)$ \\
\hline R.E.N.A.L. score, median (IQR) & $6(5.5-8)$ \\
\hline \multicolumn{2}{|l|}{ Tumor polarity } \\
\hline Upper pole & 8 \\
\hline Interpolar & 4 \\
\hline Lower pole & 7 \\
\hline Operation time (min), median (IQR) & $66(24-69)$ \\
\hline \multicolumn{2}{|l|}{ Pathology } \\
\hline $\mathrm{RCC}$ & $19(19)$ \\
\hline negative pathological results (\%) & $0(0)$ \\
\hline \multicolumn{2}{|l|}{ Haemoglobin(g/l),median (IQR) } \\
\hline Preoperative & $119(118-122)$ \\
\hline 3-7D after operative & $119(113.5-127)$ \\
\hline \multicolumn{2}{|l|}{ eGRF (mL/min), median (IQR) } \\
\hline Preoperative & $48.1(31.9-64.35)$ \\
\hline 1-2 $\mathrm{M}$ after operative & $46.75(36.95-64.025)$ \\
\hline Hospital length,median (IQR) & $5(4-7)$ \\
\hline \multicolumn{2}{|l|}{ Comorbidities } \\
\hline Transient gross hematuria & 2 \\
\hline Self-limiting perinephric hematomas & 1 \\
\hline
\end{tabular}

$\mathrm{mm}$ in every direction. All electrodes were arranged in parallel, and the distance between each electrode pair was $1.2-2.3 \mathrm{~cm}$. After the electrodes were put in place, ablation was set with the synchronous ECG trigger mode. Electroporation was performed with a cardiac synchronizer to ensure pulses in the ventricular refractory period and avoid arrhythmia. The discharge pulse times of each group are $70 \sim 90$ times. The pulse length was $70 \sim 90$ Ixs, the number of pulses per electrode pair was 3-13, and the average voltage was 2200$3000 \mathrm{~V}$. The electrodes were pulled out after ablation, and repeated enhanced CT scanning was simultaneously performed to assess adequateablationand to observehemorrhage or exudation. The patientreceived symptomatic and supported treatment while recovering in thepostanesthesia care unit.

\section{Follow-up}

One day, 1 week, 1 month, 3 months, 6 months, and 12 months after IRE, routine blood count, liver,and renal functions (BUN, Scr,eGFR) were evaluated. Contrastenhanced computed tomography imaging changes were evaluated immediately after IRE. Contrast-enhanced computed tomography/magnetic resonance was performed 1 month, 3 months, 6 months, 12 months and every year later. Sagittal and coronal images were reconstructed with thin-slice reconstruction. The effect of the treatment was evaluated according to American Urological Association (AUA) guidelines [1]. The radiologic definition of local recurrence was that a new enhancing tumor appeared again in the ablation zone after prior complete ablation. The radiologic definition of distant kidney recurrence was defined radiographically as tumors appearing in the contralateral kidney or other areas far away from the ablation zone.

\section{Statistical analysis}

Statistical analysis for all 19 tumors in the 15 patients was applied to compare serum creatinine andeGFR before and after the IRE procedure. Analysis was accomplished using SPSS 22.0 (IBM Corp, U.S.A.) for the paired t test. $P<0.05$ was considered statistically significant. Excel was used for descriptive statistics.

\section{Results}

Technical success was achieved in $100 \%$ of patients. Fifteen cases $(100 \%)$ were followed, and no patient was lost to follow-up, with a median follow-up time of 30 (IQR 14-34.5) months. The median tumor diameter was 2.4 (IQR 1.3-2.9) $\mathrm{cm}$. No patients had severe adverse reactions (above stage 3 of the Clavien-Dindo complication classification) $[3,4]$. Complications, such as injury of the ureteral collecting system, urinary fistula,uroschesis,emboli or infarcts in the kidney caused by ablation and reported in the pertinent literature, did not occur. Six patients had tolerable light pain at the puncture point. In 1 patient,immediately after the operation,a small amount of perirenal exudation was observed, which disappeared on CT imaging 1 month after the procedure. Self-limiting perinephric hematomas occurred in 1 patient and were obviously reduced 1 month later. The patient's immediate post treatment haemoglobin was $98 \mathrm{~g} /$ 1. After 3 days of conventional rehydration and hypervolemic treatment, the hemoglobin was $110 \mathrm{~g} / \mathrm{l}$. Two patients were found to have macroscopic haematuria, the immediate post treatment haemoglobin was $119 \mathrm{~g} / \mathrm{l}$ 和 $105 \mathrm{~g} / \mathrm{l}$. After 3 days of conventional rehydration and hypervolemic treatment, the hemoglobin was rechecked as $120 \mathrm{~g} / \mathrm{l}$ and $103 \mathrm{~g} / \mathrm{l}$. In addition, the patient who was found to have perinephric haematoma also got a routine inspection. Five patients presentedmicroscopichematuria 1 day after theprocedure. Transient gross hematuria occurred in 2 patients (centrally located). Without specifictreatment, the symptom of hematuria was relieved in 3 $\sim 5$ days.

Complete ablation was achieved in all 19 lesions in the immediately contrast-enhanced CT imaging changes, while the normal renal parenchyma vascular structure was well preserved (Figs. 1, 2, 3). The median IRE time was 66 (IQR 24-69) min. The median number of total 

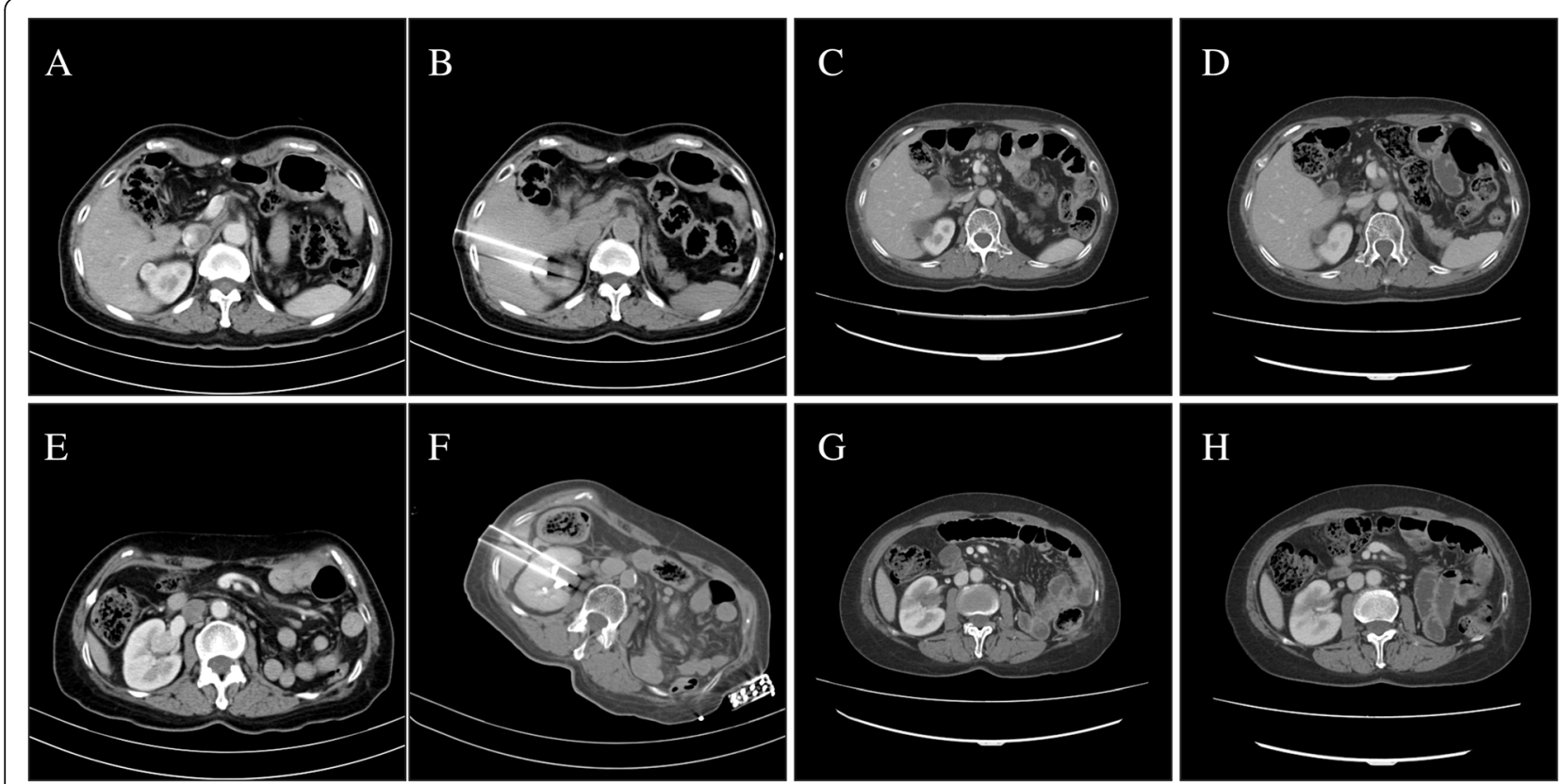

Fig. 1 Solitary kidney patient with two RCC lesions. a-d The tumor located in the upper pole of the right kidney with the needle transhepatic approach showed no contrast enhancement 1 month (c) and 3 months (d) after IRE. e-h The tumor was adjacent to the renal pelvis with the needle transhepatic approach. Contrast-enhanced CT images obtained 1 month $(\mathbf{g})$ and 3 months $(\mathbf{h})$ after IRE demonstrated no enhancement in a well-circumscribed healing area without damage to the renal pelvis or large hilar vessels

pulses was 1706(IQR 850-1990). During thefollow-up period, complete ablation was accomplished in 14 of 15 patients (93.3\%). The patients' CT appearancesincluded low density and nonenhancement. Residual enhancement was noted in 1 of the 15 patients (6.67\%) 12 months after the IRE procedure by enhancedCT scan. Subsequently, this patientaccepted salvage IRE therapy. Distant metastasis was observed in 1 patient in the needle puncture track, and the metastatic lesion was surgically removed. The other patients had no evidence of recurrence found on the follow-upimaging. There were no significant differences in the Scr before and after (last follow-up) the IRE procedure $(P>0.05)$, even in one patient withrenal dysfunction.

\section{Discussion}

Current guidelines consider thermal ablation as an alternative to nephron-sparing surgery (NSS) for patients who have renal dysfunction or have no surgical indication [6]. Recently, the long-term efficacy of ablative
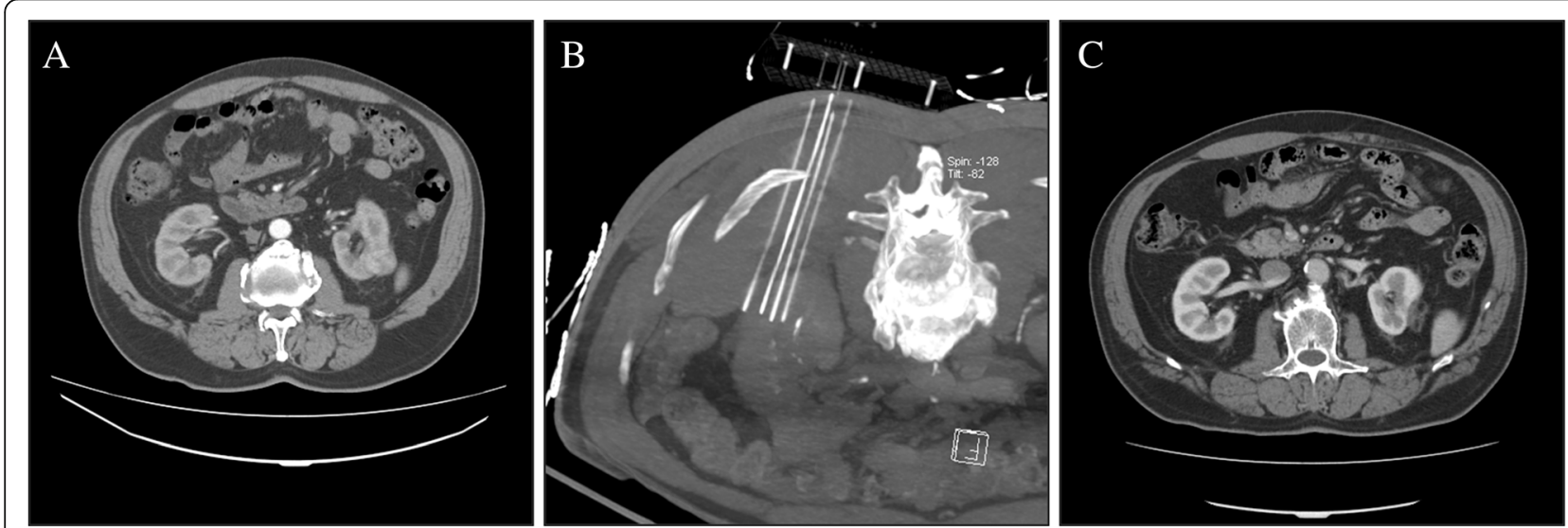

Fig. 2 a Contrast-enhanced CT transversal image before IRE with the tumor located in the middle pole of the left kidney. b Reconstructions of the CT scan after the placement of four needles. c Contrast-enhanced CT axial image 18 months after IRE. The renal mass showed no contrast enhancement. The maximal diameter of the tumor was reduced compared with that in the baseline image 

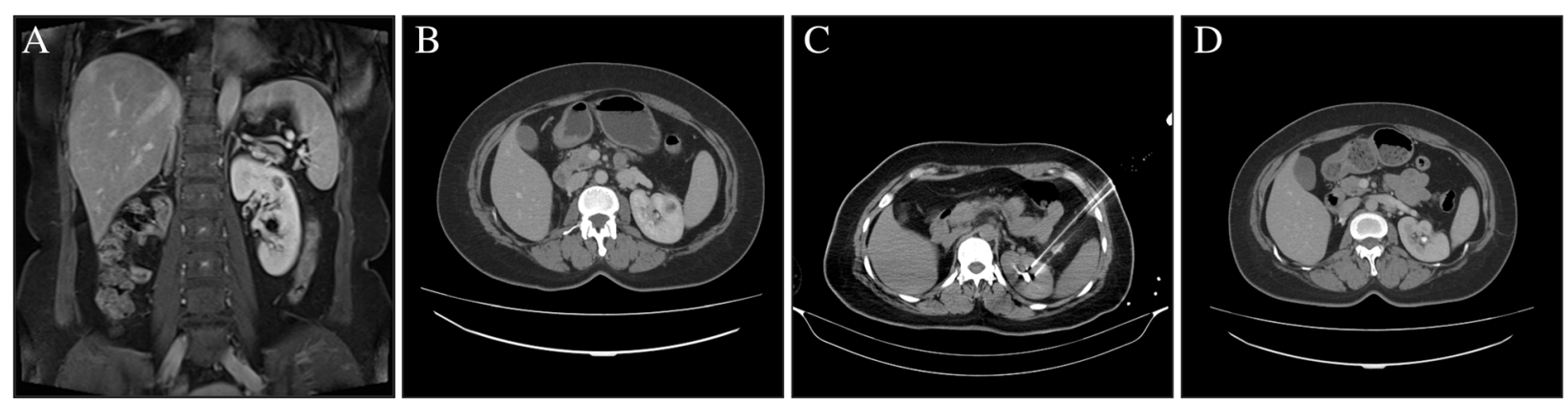

Fig. 3 a-b Contrast-enhanced MRI coronal image and contrast-enhanced $C T$ transversal image with the tumor located in the upper pole of the right kidney. c The needles were placed percutaneously through the left colon-spleen space with CT guidance. $\mathbf{d}$ Contrast-enhanced CT axial image 15 months after IRE. The kidney parenchyma atrophied, and the tum

therapy has been reported to be comparable to the outcome of surgical resection, with the greatest retention of renal function and few major complications. Ablative therapy is a minimally invasive treatment that maximizes nephron retention and is usually appropriate for patients who are ineligible for surgical resection, have only a solitary functioning kidney or have combined renal dysfunction [7]. By using electric pulses to create nanopores in the cell membrane of tumor cells, IRE will eventually induce cell apoptosis. Since the scope of IRE is limited to the cell membrane, the other extracellular matrix structuresare not affected, which allows the rapid regeneration of normal tissues.

Compared with the decrease in renal function after thermal ablation for RCC [8], no significant changes in renal function or serious complications ofIRE treatment forRCC have been reported in the literature. Noah E. Canvasser et al. [9] chose 42 cT1a RCC lesions from 41 patients with IRE. The initial treatment success rate was 93\%(39/42), and the 2-year local-recurrence-free survival (LRFS) was 83\%.No major complications occurred. Steffen J. Diehl et al. [10] described a series of 5 patients with 7 potentially malignant renal lesions in a solitary kidney treated with IRE. The author reported no significant decrease in eGFR over 3 months, even though 1 patient's eGFR decreased from $>60 \mathrm{ml} / \mathrm{min} / 1.73 \mathrm{~m} 2$ to 44 $\mathrm{ml} / \mathrm{min} / 1.73 \mathrm{~m} 2$. In our study, there were no significant changes in serum creatinine, serum urea nitrogen and eGFR after IRE therapy compared with the corresponding values before IRE in 15 patients, including 1 patient with nephrotic syndrome and 7 patients with a solitary kidney. Moreover, the normal renal function was completely preserved. No serious complications (ClavienDindo grade III or above) occurred.

The presence of a "heat sink effect" in thermal ablation, such as RFA and MWA,can affect the outcome of thermal ablation in lesions close to the vessel. There is also a "warming effect" of cryoablation [10,11]. The incidence of postoperative hemorrhage, intraoperative area infection, urine leakage, ureteral injury and stricture, intestinal damage and other nontherapeutic target organs caused by ablation is relatively high $(4 \%)[12,13]$. However, IRE does not have these limitations. For centrally located kidney tumors, IRE has advantages over surgical resection and thermal ablation techniques. At the same time, compared with thermal ablation and cryoablation, IRE requires no preoperative preparation for malignant renal tumors near important organs and tissues (such as pyelostomy, ureteral stent implantation, and artificial pneumoperitoneum and ascites, etc., to protect important tissues and organs). Transient gross hematuria occurred in 2 patients with centrally located lesions without any otherserious postoperative complications inour study.

The tumor maximal diameter of patient 10 was 4.5 $\mathrm{cm}$. IRE was not recommended for this situation because the diameter exceeded the surgical indications. The guidelines also do not recommend ablation for tumors larger than $3 \mathrm{~cm}$ in diameter. At the same time, the related literature also pointed out that the risk of recurrence is higher $[1,14]$. The patient 10 chose to try the IRE treatment and had a satisfactory curative effect. Regarding the complications and deficiencies caused by IRE, the latest literature has been explored in animal experiments to find improved methods. Timothy J. O’Brien et al. [15] tested the effects of using several pulse-timing paradigms on electrical current, tissue temperature, and tissue treatment size. They believe that cycled pulsing patterns may hold promise for enhancing the efficacy of IRE application in clinical practice and could lead to better overall outcomes for patients. N. Beitel-White et al. [16] found that larger overall changes in output current are correlated with larger decreases in $\mathrm{T}$ cell populations $24 \mathrm{~h}$ after treatment. Real-time decisions can be made regarding the optimal follow-up therapy based on the range of output current delivered during treatment. This approach will also maximize the immunomodulating effect of IRE in synergy with follow-up immunotherapy. 
Safe and successful CT-guided percutaneous ablation of RCC by IRE begins with careful preprocedural evaluation of imaging to plan the appropriate patient position, needle approach, and trajectory. The kidney is surrounded by the liver, diaphragm, lower lobe of the lung, vertebral bodies, spleen, and bowel. Given the anatomical relationship of the kidney and its surrounding organs, a suitable approach should be used according to the location of the tumor to avoid major complications related to the puncture procedure, such as scarring with ureteropelvic junction obstruction, neuromuscular injury, and bowel wall perforation.

It has been reported in the relevant literature that thermal ablation of renal tumors via the anterior approach is considered to be a relative contraindication. The main reason is the risk of percutaneous ablationrelated complications, such as damage to nontarget organs, including the small intestine, pancreas, colon,etc. [17, 18]. Hegg et al. [19] reported 18 patients (19 tumors) who underwent transhepatic renal RFA procedures by ultrasound guidance without the development of major complications during the procedures. Ginat et al. [20] described several bowel displacement and protection techniques during percutaneous renal tumor thermal ablation to avoid potential devastating consequences. In our treatment experience, CT guidance is the more suitable method for the IRE procedure because of its ability to reveal the detailed anatomy along the electrodeneedle pathway. The transhepatic approach is safe forthe treatment of tumors located anterolaterally in the right kidney. The left colon-spleen space is appropriate for tumors located at the anterior border of the left kidney. Most tumors located in the lateral and posterior part of the kidney are suitable for a posterior approach. Combined with other literatures and our experience, we can explain the ideal patient, candidate to IRE. First, it is reserved for patients who have not the surgical indication, or are prone to have postoperative complications and the patient who are not willing to accept surgical treatment. Second, IRE is suitable for the patients with higher risk of postoperative complications after thermal ablation (patients with tumor close to the urinary collection system, vital organs and great vessels, or with high R.E.N.A.L. score). Third, patients with renal insufficiency or patient who has a solitary kidney are also the ideal candidate for IRE treatment.

The current study is limited by its retrospective nature. There was no comparison arm of patients. The patient sample size wassmall, and the follow-up time was relatively short. In recent years, IRE technology for RCC has remained relatively less developed globally,and thus, the safety and efficacy of this treatment need to be further clarified through a prospective study design with a larger sample size.

\section{Conclusions}

According to the initial study results, percutaneous treatment of renal malignant tumors with IRE appears to be a safe, effective and feasibletherapy for RCC. The IRE technique has demonstrated a good therapeutic effect and protects renal function in patients without surgical indications,even with centrally located lesions. The present study may help to better plan appropriate patient positions, needle approaches, and trajectories.

\section{Abbreviations}

IRE: Irreversible electroporation; RCC: Renal cell carcinoma; eGFR: Estimated glomerular filtration rate; RFA: Radiofrequency ablation; EUA: European association of urology; MWA: Microwave ablation; INR: International normalized ratio; TBIL: Total bilirubin; DBIL: Direct bilirubin; BUN: Blood urea nitrogen; Scr: Serum creatinine; AUA: American urological association; NSS: Nephron-sparing surgery; LRFS: Local-recurrence-free survival

\section{Acknowledgements}

Not applicable.

\section{Authors' contributions}

This retrospective study was approved by the institutional review board. [ZYW]1, JL, and ZMW made contributions to the conception and design of the work. [ZYW]2, WH, and JG made contributions to the acquisition and analysis of data. [ZYW]1, CYW, QBW, and QL made contributions to the interpretation of data. [ZYW]1, JL, ZMW, YZ, and XYD had drafted the work and substantively revised it. All authors read and approved the final manuscript.

\section{Funding}

This work was supported by Clinical key specialist construction project of Shanghai municipal health commission (Interventional Radiology [No. shslczdzk06002] \& 3D Printing [No. shslczdzk07002]), who provided support for the conduct of the research and the collection of the data. This work was also supported byShanghai Municipal Key Clinical Specialty (No. ZK2019A02) andShanghai Huangpu District Youth Project (No. HKQ201803), who provided support for the study design. The above foundations are all related to the content of the article.

\section{Availability of data and materials \\ The datasets used and/or analysed during the current study are available from the corresponding author on reasonable request.}

\section{Ethics approval and consent to participate}

This study was approved by the ethics committee of Ruijin Hospital affiliated to Shanghai Jiaotong University of Medicine.

\section{Consent for publication}

Not applicable.

\section{Competing interests}

The authors declare that they have no competing interests.

\section{Author details}

'Department of Radiology, Ruijin Hospital, School of Medicine, Shanghai Jiao Tong University, 197\#, Rui Jin Er Road, Shanghai 200025, People's Republic of China. ${ }^{2}$ Department of Radiology, Ruijin Hospital Luwan Branch, School of Medicine, Shanghai Jiao Tong University, 149\#, South Chongqing Road, Shanghai 200020, People's Republic of China.

Received: 2 October 2020 Accepted: 19 January 2021

Published online: 05 February 2021

\section{References}

1. Campbell S, Uzzo RG, Allaf ME, Bass EB, Cadeddu JA, Chang A, Clark PE, et al. Renal mass and localized renal Cancer: AUA guideline. J Urol. 2017; 198:520-9. 
2. Golberg A, Yarmush ML. Nonthermal irreversible electroporation: fundamentals, applications, and challenges. IEEE Trans Biomed Eng. 2013;60: 707-14

3. Wendler JJ, Pech M, Fischbach F, Jurgens J, Friebe B, Baumunk D, Porsch M, et al. Initial assessment of the efficacy of irreversible electroporation in the focal treatment of localized renal cell carcinoma with delayed-interval kidney tumor resection (irreversible electroporation of kidney tumors before partial nephrectomy [IRENE] trial-an ablate-and-resect pilot study). Urology. 2018;114:224-32.

4. Filippiadis DK, Binkert C, Pellerin O, Hoffmann RT, Krajina A, Pereira PL. Cirse quality assurance document and standards for classification of complications: the Cirse classification system. Cardiovasc Intervent Radiol. 2017:40(8):1141-6.

5. Khalilzadeh O, Baerlocher MO, Shyn PB, Connolly BL, Devane AM, Morris CS, Cohen AM, et al. Proposal of a new adverse event classification by the society of interventional radiology standards of practice committee. J Vasc Interv Radiol. 2017;28(10):1432-1437. e3.

6. Ward RD, Tanaka H, Campbell SC, Remer EM. 2017 AUA renal mass and localized renal Cancer guidelines: imaging implications. Radiographics. 2018: 38(7):2021-33

7. Wu J, Chang J, Bai HX, Su C, Zhang PJ, Karakousis G, Reddy S, et al. A comparison of Cryoablation with heat-based thermal ablation for treatment of clinical T1a renal cell carcinoma: a national Cancer database study. J Vasc Interv Radiol. 2019;30(7):1027-33 e3.

8. Matsui Y, Hiraki T, Gobara H, Iguchi T, Tomita K, Uka M, Araki M, et al. Percutaneous thermal ablation for renal cell carcinoma in patients with BirtHogg- Dubé syndrome. Diagn Interv Imaging. 2019;100(11):671-7.

9. Canvasser NE, Sorokin I, Lay AH, Morgan MSC, Ozayar A, Trimmer C, Cadeddu JA. Irreversible electroporation of small renal masses: suboptimal oncologic efficacy in an early series. World J Urol. 2017;35(10):1549-55.

10. Diehl SJ, Rathmann N, Kostrzewa M, Ritter M, Smakic A, Kriegmair MC SSO. Irreversible electroporation for SurgicalRenal masses in solitary kidneys:shortterm interventional andFunctional outcome. J Vasc Interv Radiol. 2016;27(9): 1407-13.

11. Welch BT, Shah PH, Thompson RH, Atwell TD. The current status of thermal ablation in the management of T1b renal masses. Int J Hyperth. 2019;36(2): 31-6.

12. Zhou W, Herwald SE, McCarthy C, Uppot RN, Arellano RS. Radiofrequency ablation, Cryoablation, and microwave ablation for T1a renal cell carcinoma: a comparative evaluation of therapeutic and renal function outcomes. J Vasc Interv Radiol. 2019;30(7):1035-42

13. Atwell TD, Carter RE, Schmit GD, Carr CM, Boorjian SA, Curry TB, Thompson $\mathrm{RH}$, et al. Complications following 573 percutaneous renal radiofrequency and cryoablation procedures. J Vasc Interv Radiol. 2012;23(1):48-54.

14. Best SL, Park SK, Youssef RF, Olweny EO, Tan YK, Trimmer C, Cadeddu JA. Long-term outcomes of renal tumor radio frequency ablation stratified by tumor diameter: size matters. J Urol. 2012;187(4):1183-9.

15. O'Brien TJ, Lorenzo MF, Zhao Y, Neal li RE, Robertson JL, Goldberg SN, Davalos RV. Cycled pulsing to mitigate thermal damage for multi-electrode irreversible electroporation therapy. Int J Hyperth. 2019;36(1):953-63.

16. Beitel-White N, Martin RCG, Li Y, Brock RM, Allen IC, Davalos RV. Real-time prediction of patient immune cell modulation during irreversible electroporation therapy. Sci Rep. 2019;9(1):17739.

17. Maciolek KA, Abel EJ, Posielski NM, Hinshaw JL, Lubner MG, Lee FT Jr, Ziemlewicz TJ, et al. Tumor location does not impact oncologic outcomes for percutaneous microwave ablation of clinical T1a renal cell carcinoma. EurRadiol. 2019;29(11):6319-29.

18. Haddad RL, Patel MI, Vladica P, Kassouf W, Bladou F, Anidjar M. Percutaneous radiofrequency ablation of small renal tumors using $\mathrm{CT}$ guidance: a review and its current role. Urol J. 2012;9(4):629-38.

19. Hegg RM, Schmit GD, Kurup AN, Weisbrod AJ, Boorjian SA, Atwell TD. Ultrasound-guided transhepatic radiofrequency ablation of renal tumors: a safe and effective approach. Cardiovasc Intervent Radiol. 2014;37(2):508-12.

20. Ginat DJ, Saad WEA. Bowel displacement and protection techniques during percutaneous renal tumor thermal ablation. Tech Vasc Interv Radiol. 2010; 13(2):66-74.

\section{Publisher's Note}

Springer Nature remains neutral with regard to jurisdictional claims in published maps and institutional affiliations.

Ready to submit your research? Choose BMC and benefit from:

- fast, convenient online submission

- thorough peer review by experienced researchers in your field

- rapid publication on acceptance

- support for research data, including large and complex data types

- gold Open Access which fosters wider collaboration and increased citations

- maximum visibility for your research: over $100 \mathrm{M}$ website views per year

At BMC, research is always in progress.

Learn more biomedcentral.com/submissions 